\title{
Effect of flow conditions on characteristics and morphological variations of urea deposits during preliminary stage in Urea-SCR Systems-A study using SEM and XRD
}

Sadashiva Prabhu S ( $\nabla$ ss.prabhu97@gmail.com )

Manipal Institute of Technology https://orcid.org/0000-0002-5364-7647

Nagaraj Shivappa Nayak

KBAT Technologies Pvt. Ltd., Pune

Kapilan Natesan

Nitte Meenakshi Institute of Technology

\section{Research}

Keywords: SCR, deposit formation, Temperature, flow rate, SEM

Posted Date: January 4th, 2021

DOI: https://doi.org/10.21203/rs.3.rs-136496/v1

License: (c) (i) This work is licensed under a Creative Commons Attribution 4.0 International License.

Read Full License 


\section{Abstract}

Urea-Water Solution (UWS) is sprayed into the diesel engine exhaust gases of automobiles to generate reducing agent $\mathrm{NH} 3$ in Urea-SCR system adopted to diesel engines of modern automobiles for the mitigation of $\mathrm{NO} x$. Although, it is a very efficient technique, the deposit formation at low temperature is a major concern. The growth of deposits not only reduces the efficiency of $\mathrm{NH} 3$ generation, but also generates non-depleting complex compounds. The temperature and Reynolds number have significant effects on these deposit formation. The compositional variation and crystallinity of deposits were experimentally investigated using EDX and XRD with respect to variation in temperature and flow rate at the preliminary stages. The elemental analysis done for different samples using EDX indicates urea as a major constituent in most of the deposits up to $2500 \mathrm{C}$ for overdosed conditions. The XRD results indicate the evolution of various traces of urea related compounds at different temperature and flow rate. Using Scanning Electron Microscopy (SEM), the morphological variations were studied. The comparative study of morphology of deposits during the initial stages of deposit formation indicates an extent to which growth can takes place and probable areas of deposits for further growth for varying exhaust gas flow rates.

\section{Full Text}

This preprint is available for download as a PDF.

\section{Figures}




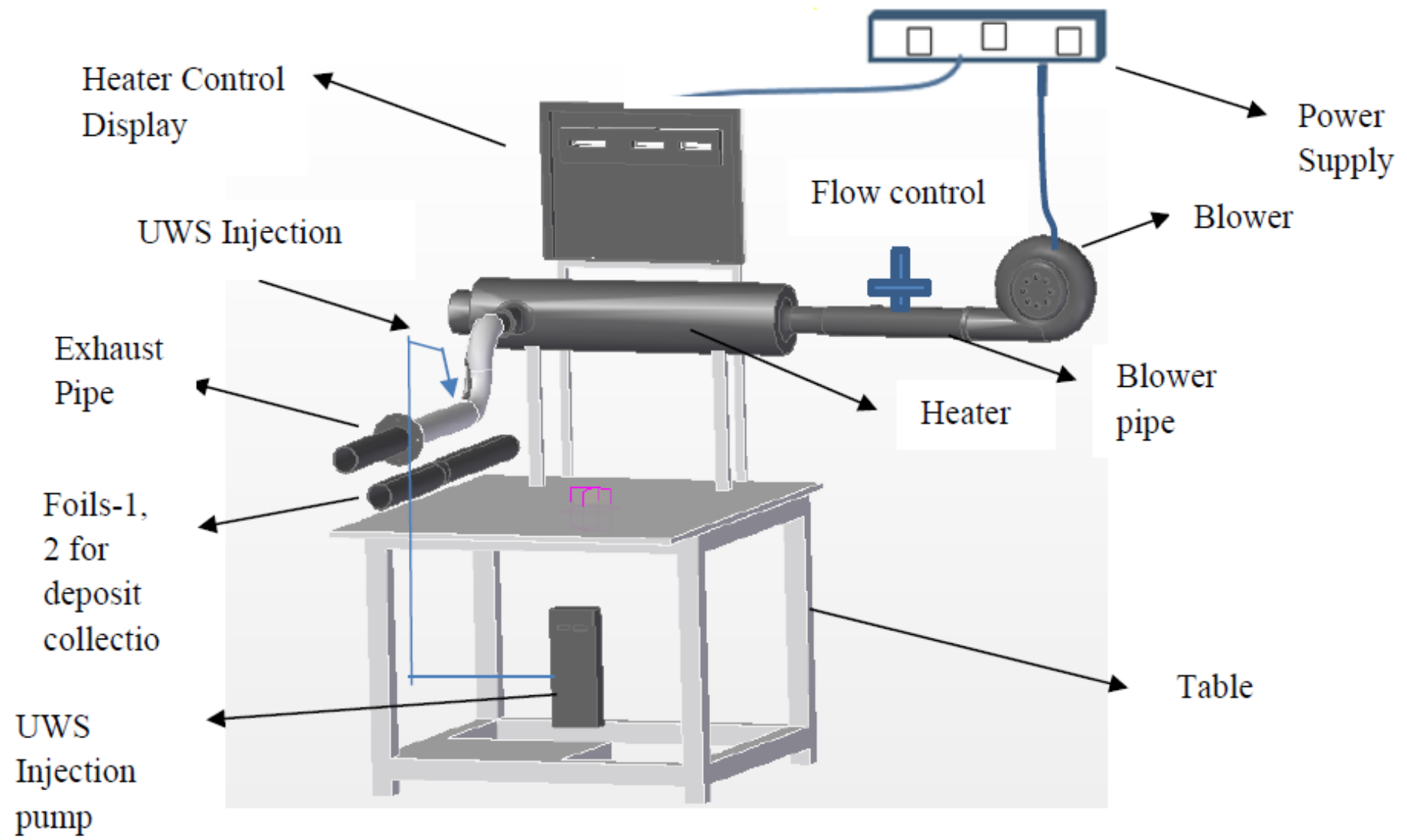

Figure 1

Experimental setup showing UWS injection and deposit formation

\section{Image not available with this version}

Figure 2

Image is not available with this version 


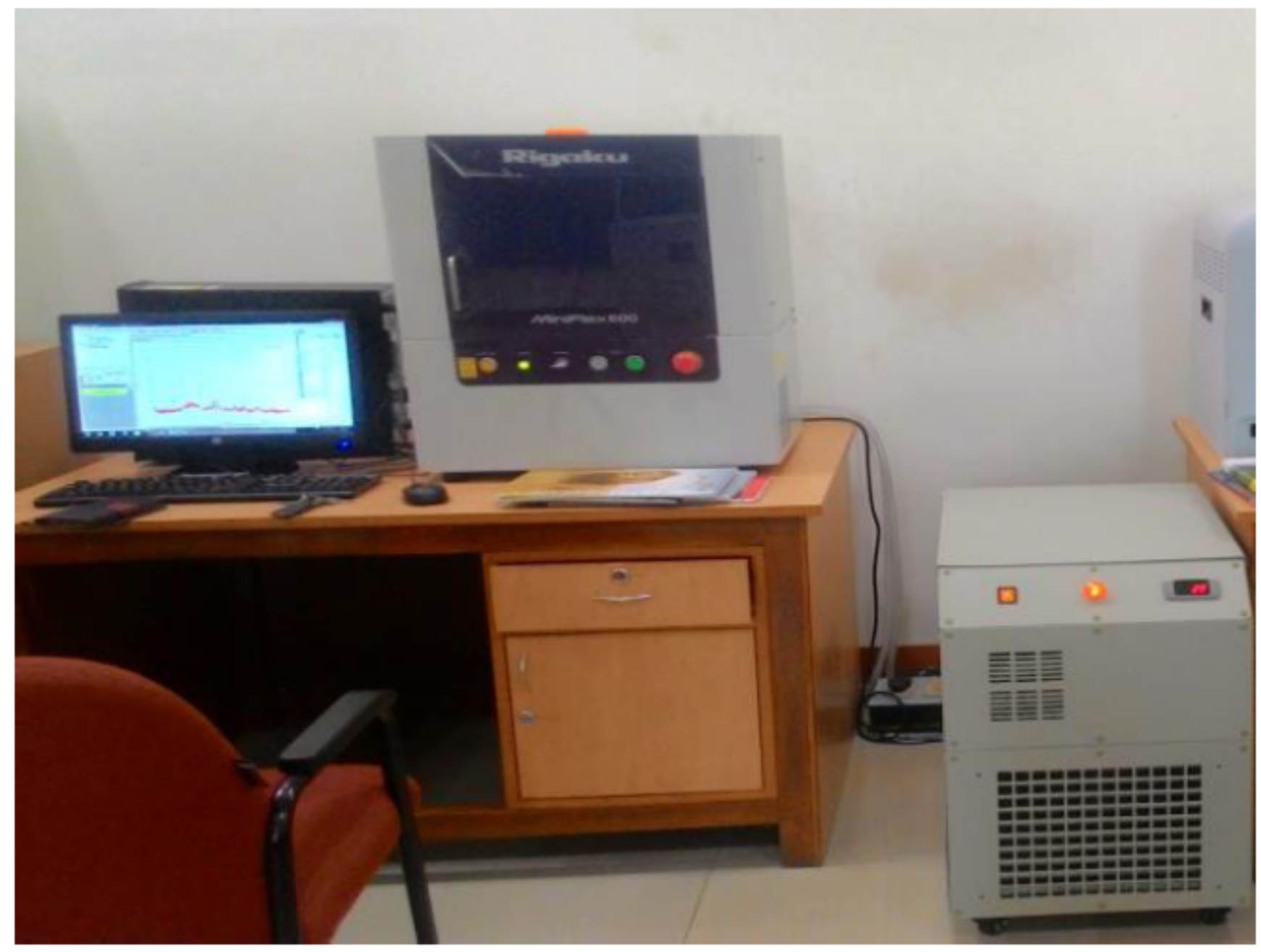

Figure 3

Powder XRD(Voltage-20-40V, Current-2-15mA along with chiller water circulation 

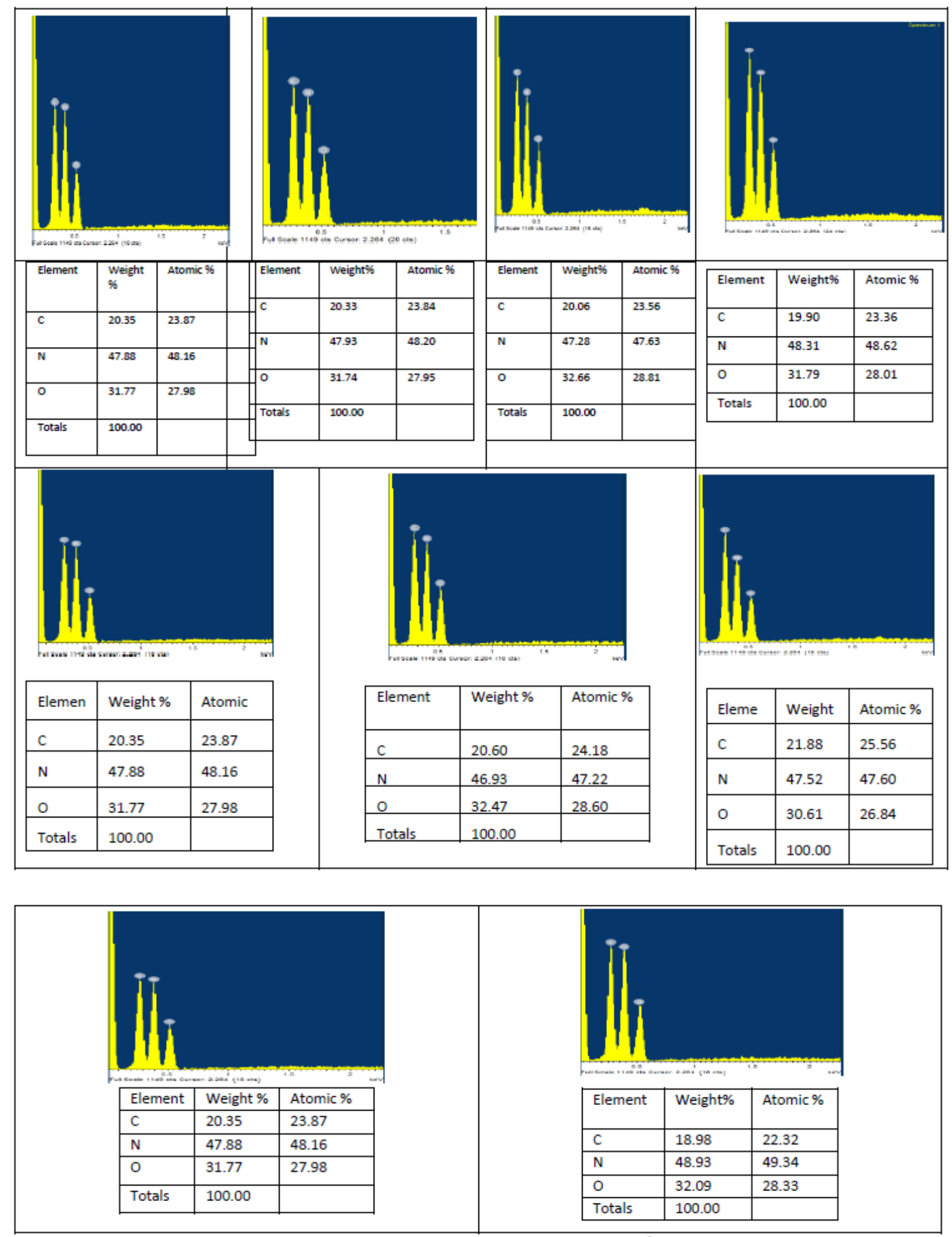

\section{Figure 4}

EDX results of urea deposits formed at a) pure urea, $150^{\circ} \mathrm{C}-34.74 \mathrm{~kg} / \mathrm{h}, 86.86 \mathrm{~kg} / \mathrm{h}, 121.6 \mathrm{~kg} / \mathrm{h} \mathrm{b}$ )pure urea,2000C-34.74kg/h, $86.86 \mathrm{~kg} / \mathrm{h}$ c)pure urea, $2500 \mathrm{C}-34.74 \mathrm{~kg} / \mathrm{h}$. 


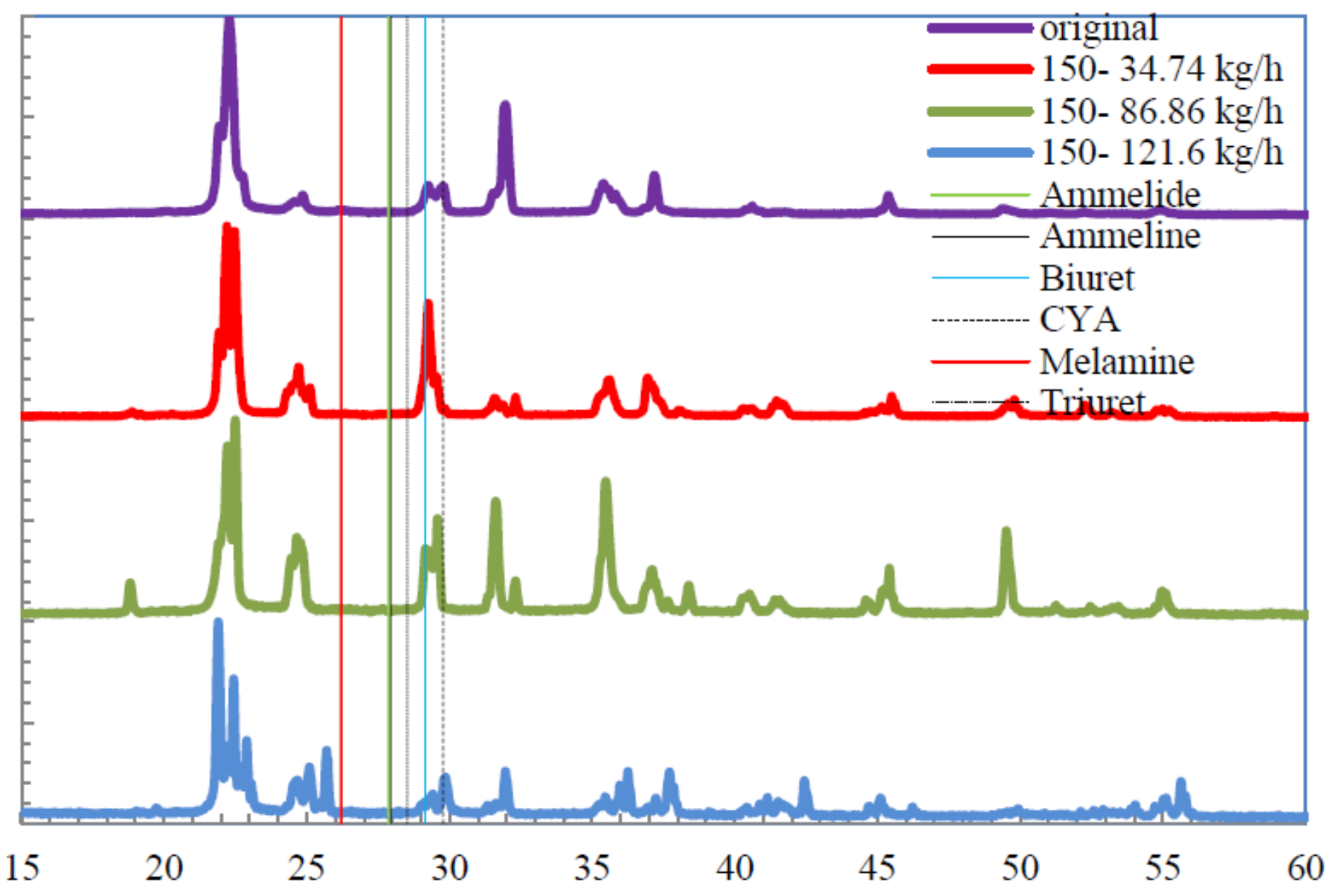

Figure 5

The comparison XRD Results of tested at various flow rates $150^{\circ} \mathrm{C}$ 

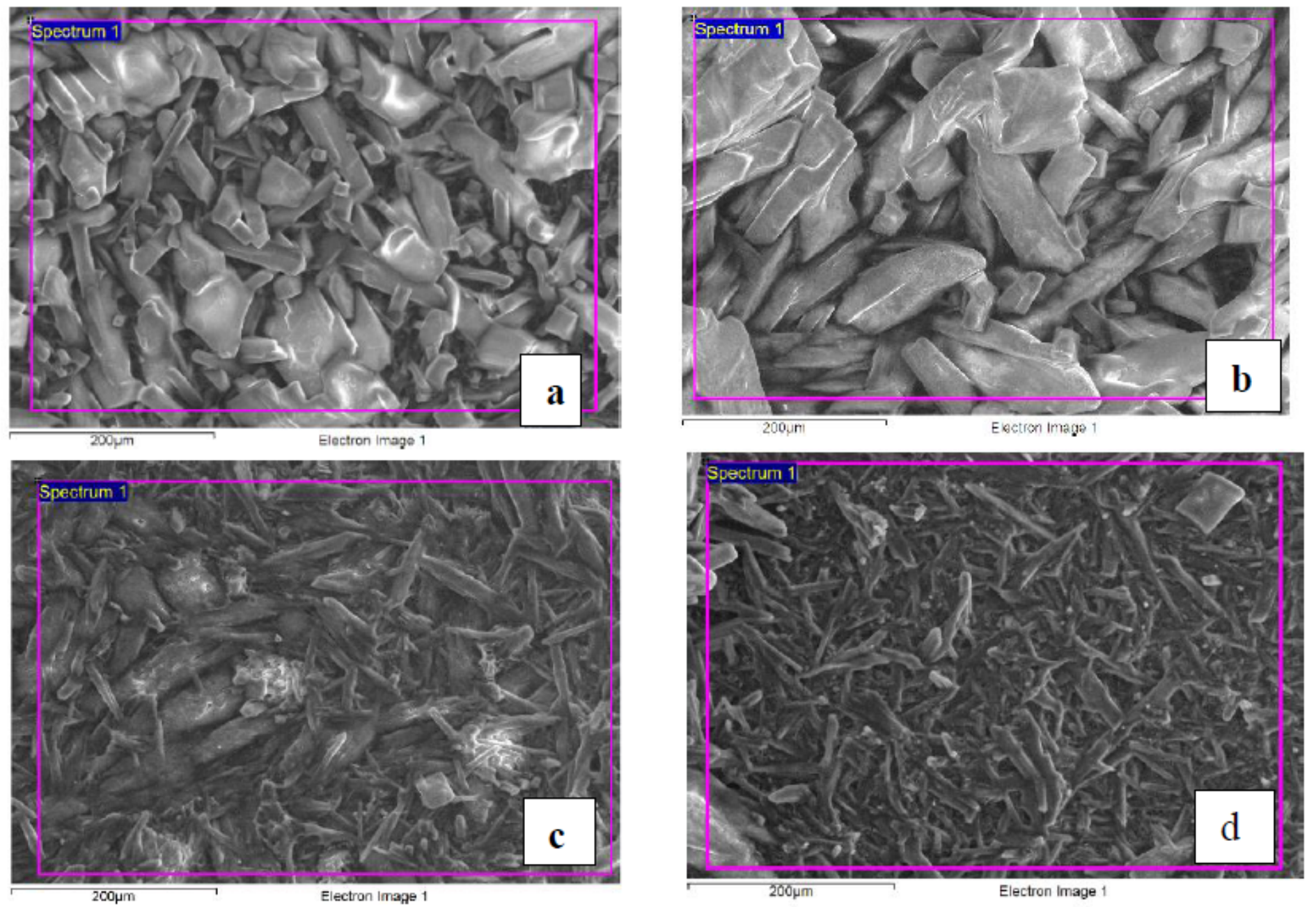

Figure 6

The morphology of samples tested at various flow rates at a)Pure Urea b) $\left.150^{\circ} \mathrm{C}-34.74 \mathrm{~kg} / \mathrm{hr} \mathrm{c}\right) 150^{\circ} \mathrm{C}$ $86.86 \mathrm{~kg} / \mathrm{hr} \mathrm{d}) 150^{\circ} \mathrm{C}-121.6 \mathrm{~kg} / \mathrm{hr}$ 


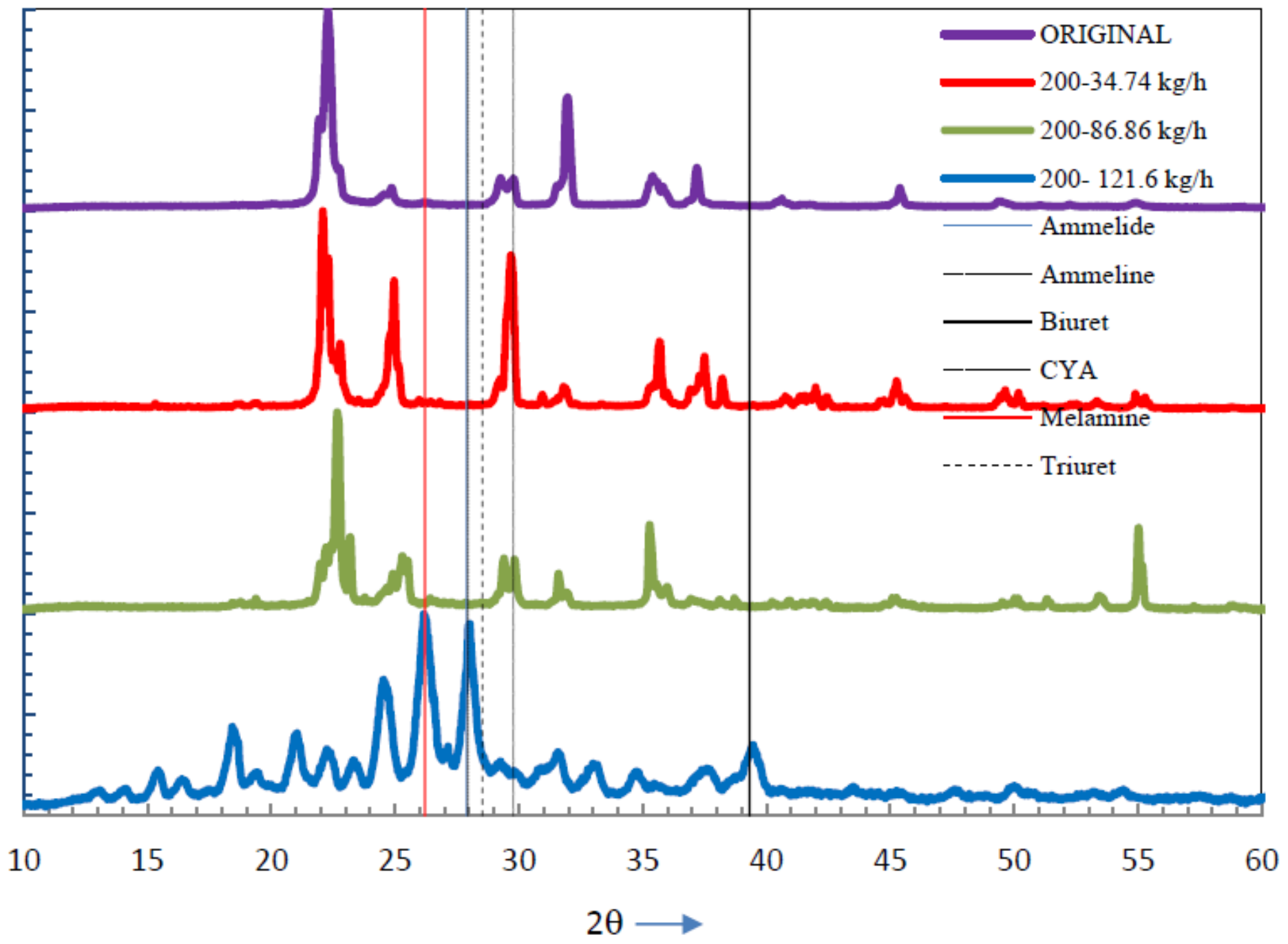

Figure 7

The comparison XRD Results of tested at various flow rates $200^{\circ} \mathrm{C}$

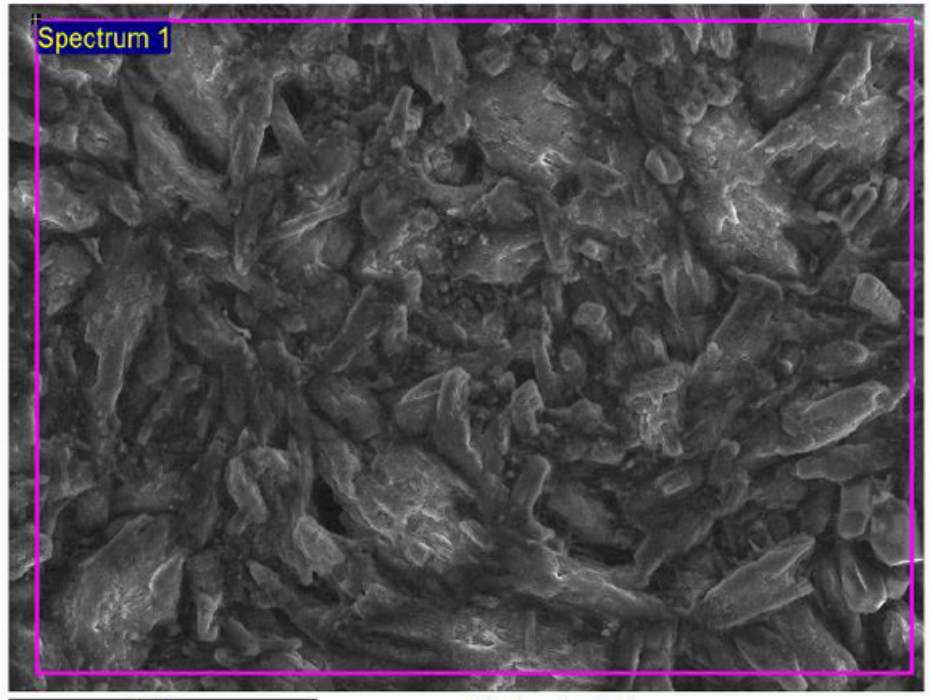

$200 \mu \mathrm{m}$

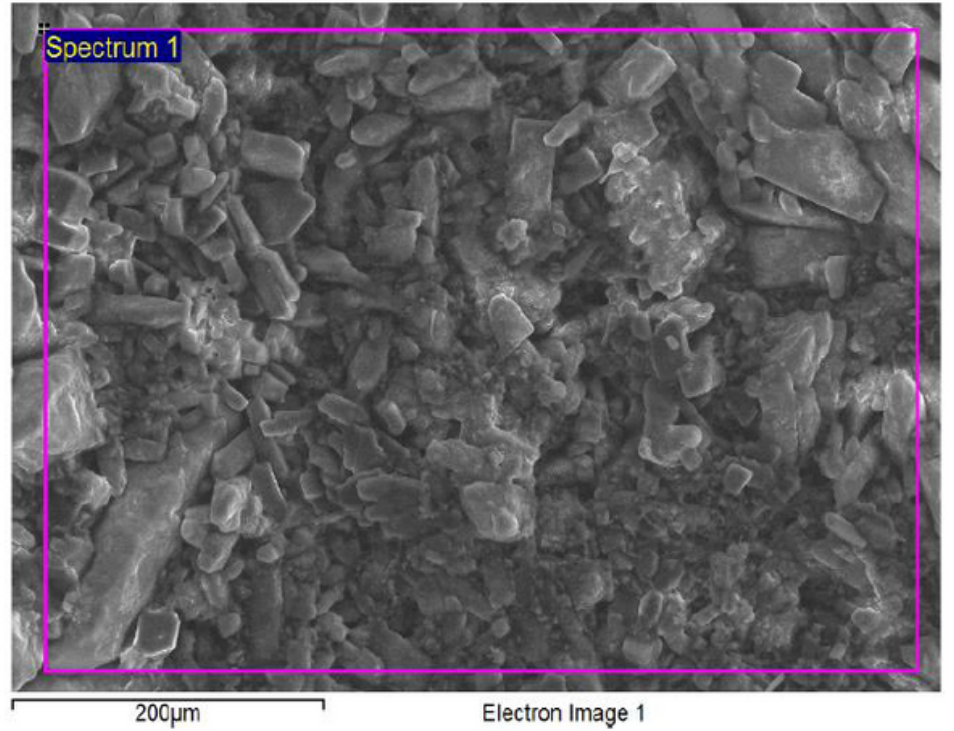

Figure 8 
The morphology of samples tested at various flow rates at $150^{\circ} \mathrm{C}$ a) $\left.34.74 \mathrm{~kg} / \mathrm{hr} \mathrm{b}\right) 86.86 \mathrm{~kg} / \mathrm{hr}$

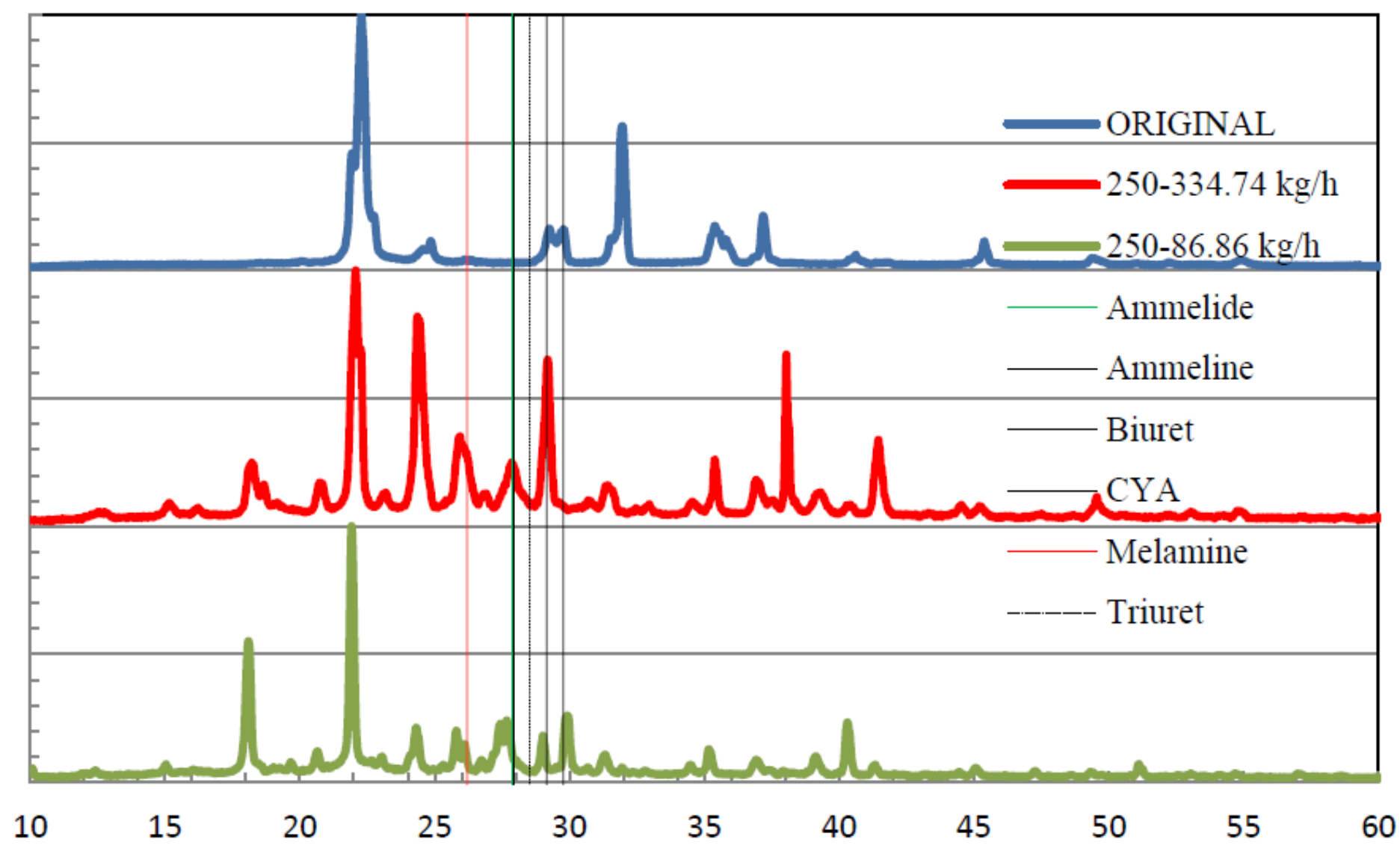

Figure 9

The comparison XRD Results of tested at various flow rates $250^{\circ} \mathrm{C}$ 


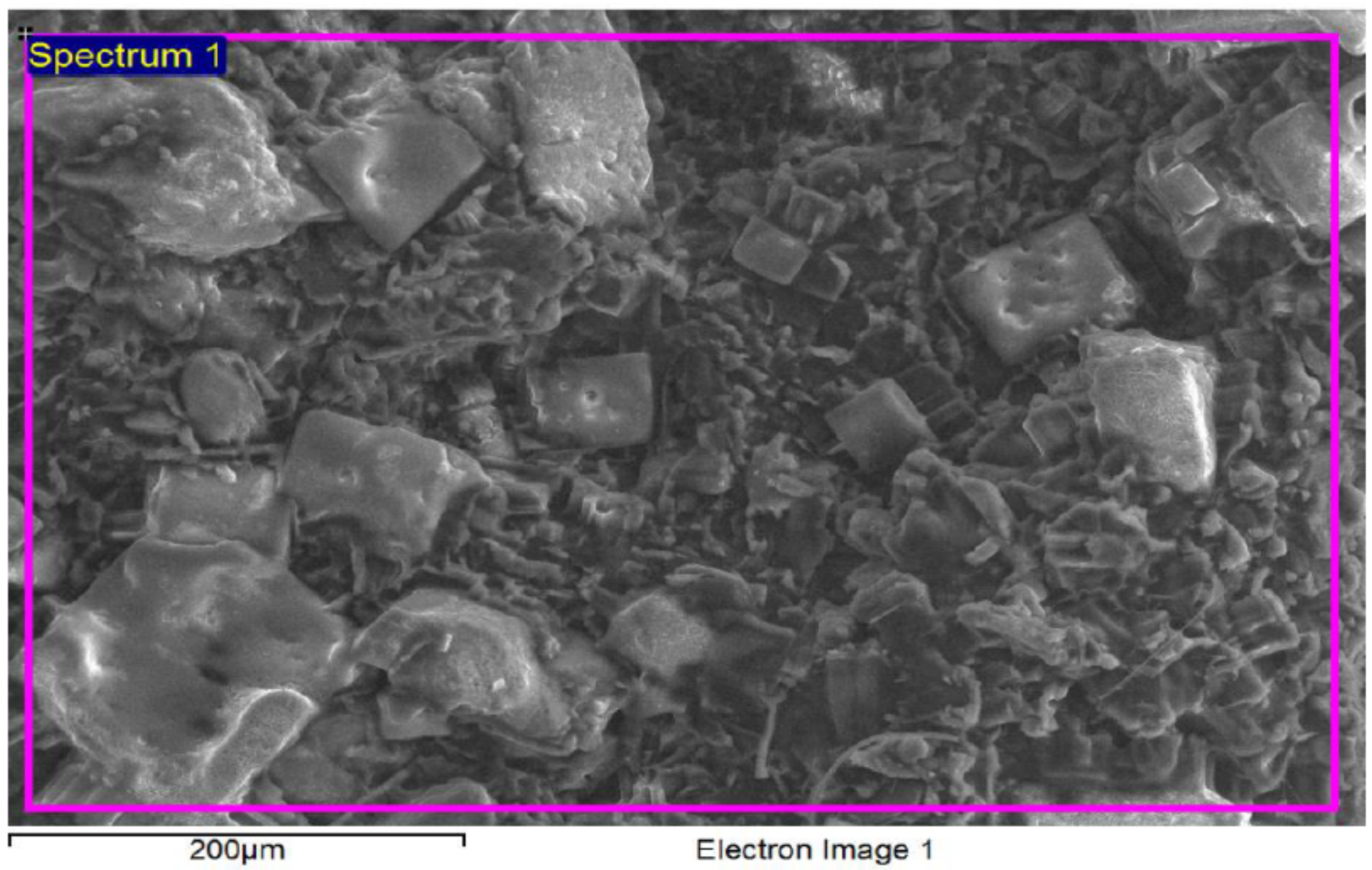

Figure 10

The morphology of samples tested at various flow rates for the sample tested at $250^{\circ} \mathrm{C}$ at $34.74 \mathrm{~kg} / \mathrm{hr}$ 